\title{
O EXCESSO DE TRABALHO MATA OU DÁ PRAZER? UMA EXPLORAÇÃO DOS ANTECEDENTES E CONSEQUENTES DO WORKAHOLISMO ${ }^{12}$
}

\author{
Jorge F. S. Gomes ${ }^{3}$ \\ Patrícia Soares 4
}

Resumo: O objectivo deste trabalho é examinar o workaholismo em termos dos seus antecedentes e consequentes. A problemática tem sido pouco tratada na literatura especializada, pelo que a investigação aproveitou esta lacuna para realizar uma análise exploratória de alguns temas associados ao workaholismo.

Utilizou-se o Work Addiction Risk Test (Robinson, 1998) para identificar os indivíduos que, numa empresa de cosméticos, maiores valores registaram no teste. Posteriormente, esses indivíduos foram entrevistados, a fim de explorar e conhecer as suas perspectivas relativamente aos conteúdos sob observação.

Os resultados encontrados permitem tecer comparações entre o que é proposto na literatura e a realidade prática. $\mathrm{O}$ artigo discute a noção de workaholismo, as suas causas, os seus efeitos sobre as pessoas, e a perspectiva dos sujeitos sobre o tópico. Contrastam-se ainda os resultados da fase quantitativa com a fase qualitativa da investigação.

Palavras-Chave: Workaholismo, trabalho, burnout, dependência do trabalho

Too much work: a killer or a pleasure? An empirical investigation of the antecedents and consequences of workaholism (Abstract): The goal of this research is to examine workaholism as far as its antecedents and consequences are concerned. The topic is generally understudied, and therefore the current research explored actors' subjective views over relevant topics in the area.

\footnotetext{
${ }^{1}$ Nota: Artigo revisto e aceite para publicação sob a responsabilidade da anterior direcção da revista Psicologia.

${ }^{2}$ Os autores agradecem a Francisco Cesário (PT Contact), e Virgílio Amaral (ISPA), pelos comentários e sugestões de melhoria a uma versão anterior deste documento.

3 ISCTE - IUL, Departamento de Psicologia Social e das Organizações, Investigador do CIS (Centro de Investigação e Intervenção Social) e do CIEO (Centro de Investigação sobre Espaço e Organizações)

Avenida das Forças Armadas, 1649-026 Lisboa; Email: jorge.gomes@iscte.pt

${ }^{4}$ Consultora Independente.
}

PSICOLOGIA, Vol. XXV (1), 2011, Edições Colibri, Lisboa, pp. 51-72 
The current research used the Work Addiction Risk Test (Robinson, 1998) in order to identify workaholics in a cosmetics company. The individuals with the highest scores were later interviewed, in order to understand their accounts and views of the subject matters under study.

Results are interesting since they allow building an initial picture of workaholism in the real world. Topics discussed are the concept of workaholism, its causes, its consequences, and what people think of the phenomenon.

Keywords: Workaholismo, work, burnout, work addiction

\section{Introdução}

Na sociedade actual as pessoas passam uma considerável parte do seu tempo a trabalhar ou a preparar-se para tal. $O$ trabalho cumpre um papel central nas suas vidas e na satisfação de diversas necessidades, sendo encarado, até, uma actividade saudável. Contudo, em alguns casos, as pessoas assumem um compromisso demasiado pesado com o trabalho em prejuízo das suas próprias vidas e da dos seus familiares. O termo workaholismo é utilizado para descrever este envolvimento excessivo com o trabalho (Seybold \& Salomone, 1994).

E, no entanto, uma dedicação integral e uma vida centrada no trabalho parece ser a regra de sobrevivência nas empresas modernas e o único caminho para alcançar sucesso na carreira (Serva \& Ferreira, 2006). Os autores fazem notar o aumento da carga de trabalho e da quantidade de horas que se consome no trabalho, assim como o maior envolvimento com a organização. No Japão este trabalho excessivo é o responsável por muitas mortes, sendo que a família de alguém que se comprova ter morrido por karōshi (morte por excesso de trabalho) tem direito a uma elevada indemnização (The Economist, 2007).

Apesar do workaholismo ser relativamente recente, alguns trabalhos já foram produzidos, ensaiando um início da análise científica que aponta para uma área de estudo relevante e promissora. Algumas das questões que guiam as pesquisas são: "o que é o workaholismo?", "como se caracteriza?", "o que o causa?", e "quais as suas consequências?".

A investigação agora reportada procura responder às duas últimas questões (antecedentes e consequências do workaholismo). O texto tem início com a revisão da literatura, explorando-se o conceito, tipologias e dimensões; depois analisam-se os antecedentes e consequências do fenómeno. A revisão culmina com o objectivo da investigação. Na segunda parte expõe-se o trabalho empírico, e por fim conclui-se tecendo as necessárias implicações teóricas, práticas, e metodológicas. 


\section{Enquadramento}

\section{Definições e Tipologias de Workaholismo}

O workaholismo foi inicialmente abordado por Wayne Oates (1971), em "Confessions of a Workaholic", onde descreve a sua própria necessidade incontrolável de trabalhar. $\mathrm{O}$ workaholismo foi então considerado um vício, uma compulsão desmedida para trabalhar incessantemente. Depois disso o termo tem sido também associado a altos níveis de stress, causa de problemas de saúde física e emocional, pobre funcionamento familiar, conflitos na vida social, e burnout (Burke, 2000; Spence \& Robbins, 1992). Para além da obsessão com o trabalho, os workaholicos são descritos como indivíduos orientados para a tarefa, compulsivos, perfeccionistas, neuróticos, rígidos, altamente motivados e capacitados, impacientes e egocêntricos (Andreassen, Ursin \& Eriksen, 2007).

Não existe um consenso no que respeita a definir ou categorizar o worksholismo, ou até mesmo em aceitar o conceito (Scott, Moore \& Miceli, 1997). Alguns autores vêm o workaholismo como algo positivo (Machlowitz, 1980; Scott et al., 1997) e outros como algo negativo (Killinger, 1991; Oates, 1971; Robinson, 1998).

Mosier (1983) define o workaholismo em termos de horas trabalhadas, proclamando aqueles que trabalham mais de 50 horas por semana como workaholicos. Machlowitz (1980), por seu lado, revela que os workaholicos são pessoas que dedicam sempre mais tempo e pensamentos ao seu trabalho do que a situação exige; isto faz com que a sua atitude perante o trabalho seja diferente dos outros colegas, e não o número de horas que trabalha.

Naughton (1987) apresentou uma tipologia de workaholismo baseada em duas dimensões: compromisso da carreira e comportamento obsessivo-compulsivo. Os workaholicos envolvidos com o trabalho (elevado compromisso com o trabalho e baixa obsessão-compulsão) apresentam um melhor desempenho em trabalhos exigentes e uma elevada satisfação com o trabalho, com um baixo interesse em actividades extra-trabalho.

Para Killinger (1991), o workaholico é um indivíduo que, numa tentativa de ser aceite, respeitado e aprovado pelos outros, faz do trabalho um meio de alcançar tal aprovação e sucesso. Os workaholicos são os "viciados respeitáveis" do nosso século e portanto não causa estranheza aos olhos de ninguém que trabalhem 12, 14 ou mais horas por dia.

Spence e Robbins (1992) propõem três dimensões no workaholismo: 'work involvement' (envolvimento com o trabalho), 'feeling driven to work' (sentimento de imposição para com o trabalho) e 'enjoyment of work' (prazer com o trabalho). Estas dimensões dão origem a três tipos de workaholicos: workaholicos, workaholicos entusiásticos (enthusiasts workaholics), e entu- 
siastas com o trabalho (work enthusiasts). Os primeiros envolvem-se e persistem muito no trabalho, retiram pouco prazer, sentem-se deprimidos quando não estão a trabalhar, e são compulsivos. Os segundos envolvem-se com o trabalho, retiram elevada satisfação, mas persistem pouco. Os últimos pontuam alto nas três componentes. De acordo com os autores, os workaholicos são sempre mais perfeccionistas, experimentam maior stress e mais problemas de saúde. Num estudo com 174 sujeitos, Aziz e Zickar (2006) confirmam que os workaholicos revelam um padrão de atributos que corresponde ao de uma síndrome multifacetada.

Scott et al. (1997) identificaram três tipos de comportamentos workaholicos: compulsivo-dependente, perfeccionista e orientado para a realização. As características que compõem esses padrões são analisadas como variáveis contínuas; assim, os padrões não são mutuamente exclusivos e um workaholico pode ser uma combinação de qualquer dos dois ou de todos os três tipos. Uma outra contribuição dos autores é a definição dos elementos básicos para a identificação de indivíduos com padrões de comportamento workaholico: tais indivíduos gastam uma grande parte do seu tempo em actividades de trabalho, dando demasiada importância ao mesmo, abdicando de outros aspectos sociais - família, amigos, lazer, entre outros; eles persistem em pensar frequentemente em assuntos de trabalho, mesmo quando não estão efectivamente a trabalhar; eles trabalham muito além do que é razoavelmente esperado do cargo que ocupam, ou do que para atender as suas necessidades económicas básicas. Esta definição é a adoptada ao longo deste estudo.

Scott et al. (1997) sugerem que o workaholismo é um fenómeno abrangente que tem implicações para ambos os domínios, trabalho e fora do trabalho. Deste modo, examinaram o workaholismo no contexto destes dois domínios. Em primeiro lugar, parece haver um impacto negativo do workaholismo no funcionamento familiar, havendo inclusive influência nos níveis de depressão e ansiedade nos filhos de pais workaholicos (Robinson \& Kelley, 1998). Por outro lado, um estudo de Burke (2001) revelou não haver relação entre aumento de salário e satisfação na carreira ou comportamento workaholico, isto é, os workaholicos podem trabalhar mais que os outros funcionários sem receberem mais por isso, o que é coerente com a ideia de que são motivados por forças internas e não por factores externos. Por fim, e apesar das semelhanças entre um workaholico e a personalidade tipo A discutidas por vários autores, os estudos revelam modestas correlações entre os dois constructos (McMillan et al., 2001; citado por Taris, Schaufeli \& Verhoeven, 2005). Num estudo mais recente, Andreassen, Hetland e Pallesen (2010), corroboram esta linha de pesquisa, ao encontrar associações positivas fracas entre algumas dimensões personalísticas e as componentes do workaholismo (e.g. a conscienciosidade relaciona-se modestamente com as três dimensões de envolvimento com o trabalho, drive, e prazer com o trabalho). 


\section{Dimensões do Workaholismo}

$\mathrm{Ng}$, Sorensen e Feldman (2007) propõem várias dimensões do workaholismo (figura 1).

Figura 1 - Modelo teórico proposto por Ng, Sorensen \& Feldman (2007)

\section{Antecedentes}

\begin{tabular}{|l|}
\multicolumn{1}{c|}{ Disposições } \\
- Auto-estima \\
- Traços relacionados com \\
realização \\
- Valores relacionados com \\
realização
\end{tabular}

Experiências Socioculturais - Infância disfuncio-

nal/experiências familiares

- Aprendizagem vicariante em casa

- Aprendizagem vicariante no trabalho

- Competição no trabalho

- Maior auto-eficácia no traba-

lho do que em actividades extra-laborais

Atitude Comportamental - Recompensas tangíveis e intangíveis

- Sistema do winner-takes-all

- Ênfase no input em detrimento

do output

- Ambiente organizacional
Dimensões de Workaholismo
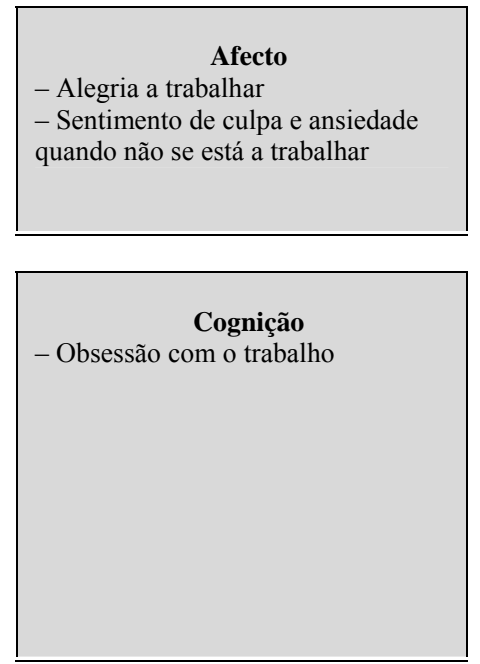

Comportamento

- Excesso de horas a trabalhar

- Misturar o trabalho com a vida

pessoal

\section{Consequências}
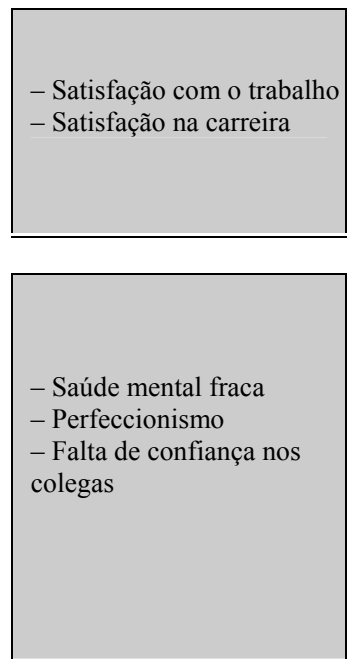

- Sucesso extrínseco da carreira

- Relações sociais pobres - Fraca saúde física

Estes autores enfatizam a noção de dependência, e na sequência enfatizam três dimensões: afectiva, cognitiva e comportamental ( $\mathrm{Ng}$ et al., 2007). Os workaholicos são definidos como aqueles que retiram prazer do acto de trabalhar, que estão obcecados pelo trabalho, e que investem longas horas e tempo livre pessoal a trabalhar. Em suma, são pessoas cujas emoções, pensamentos e comportamentos, são fortemente dominados pelo seu trabalho.

Todo este conhecimento acumulado sobre o tema revela que o fenómeno é mais intrincado do que se poderia inicialmente pensar; e mostra 
igualmente alguma discordância entre os autores. No entanto, há alguma concordância relativa ao facto do workaholismo estar associado a consequências adversas à saúde e a uma reduzida satisfação com a família e com as relações interpessoais (Burke, 2000; Killinger, 1991; Robinson, 1998). Os estudos empíricos são relativamente poucos (Andreassen et al. contabilizavam 17 em 2007), o que indica um campo tremendo para exploração e investigação. Dois temas pouco explorados são o das causas e antecedentes do workaholismo, e o das suas consequências e impactos.

\section{Antecedentes do Workaholismo}

Existem três perspectivas teóricas sobre as causas do workaholismo (Ng et al., 2007): disposições individuais, experiências socioculturais e comportamentos reforçados pelo ambiente. As três perspectivas sugerem que os indivíduos se tornam workaholicos porque possuem certos traços de personalidade (Scott et al., 1997), as suas experiências sociais ou culturais promovem workaholismo (Oates, 1971; Robinson \& Post, 1995), ou os seus comportamentos workaholicos são repetidamente reforçados.

No que concerne a perspectiva disposicional, Ng e colegas (2007) sugerem que uma das influências mais importantes é a auto-estima. Uma vez que o comportamento aditivo é tido como algo que procura paralisar ou evitar sentimentos negativos associados a outras actividades ou envolvimentos (Porter, 1996), os indivíduos com baixa auto-estima estão mais propensos a comportamentos aditivos do que outros (Robinson \& Kelley, 1998), e como tal estão mais predispostos a tornarem-se workaholicos.

Os traços de personalidade relacionados com a realização (por exemplo, personalidade Tipo A, personalidade obsessivo-compulsiva, necessidade de realização) podem de igual modo predispor os indivíduos a tornarem-se mais dependentes do trabalho (Liang \& Chu, 2009). Outro factor com peso é o dos valores humanos. Segundo Schwartz (1992, citado por Ng et al., 2007) o valor de realização reflecte o desejo de ser bem sucedido, capaz, ambicioso e influente; e o valor de auto-orientação reflecte um rumo dirigido para a independência. Estes valores tendem a predispor os indivíduos a tornarem-se excessivamente focados no seu trabalho e no êxito da carreira e, por conseguinte, geram um sentimento de que o trabalho é uma das tarefas mais centrais da vida, senão a mais central. No que diz respeito às variáveis demográficas, os estudos são ainda poucos e inconclusivos. Numa rara incursão por estes domínios, Aziz, Adkins, Walker e Wuensch (2010), não encontraram diferenças entre pessoas de raça caucasiana e raça negra no que diz respeito aos níveis de workaholismo. Já Gorgievski, Bakker e Schaufeli verificam em 2010 que o nível de workaholismo é superior em empregados por conta própria comparativamente aos trabalhadores por conta doutrem. 
A perspectiva sociocultural sugere que a dependência é geralmente o produto das experiências sociais e culturais a que os indivíduos assistem na sua infância, adolescência e fase adulta (Thombs, 1994, citados por $\mathrm{Ng}$ et al., 2007). As experiências sócioculturais têm a sua origem na família ou no local de trabalho. Do lado familiar, um leque de experiências negativas pode precipitar o workaholismo, e o trabalho pode ser visto como um modo socialmente aceite de evitar a família.

Por fim, alguns trabalhos sugerem que o workaholismo é o resultado de reforços positivos de comportamentos workaholicos ou da falta de punição dessas acções. Esta perspectiva concentra-se mais nos comportamentos workaholicos e menos nas suas dimensões afectiva e cognitiva ( $\mathrm{Ng}$ et al., 2007). Num interessante trabalho de Chamberlin e Zhang (2009), realizado com 347 estudantes do ensino secundário, descobriu-se que o workaholismo dos adolescentes está positivamente relacionado com o workaholismo percebido dos seus pais.

\section{Consequências do Workaholismo}

A maioria das investigações em relação às consequências do workaholismo é focalizada no seu lado negativo (ex: Killinger, 1991). Burke (2001) descreve os workaholicos como infelizes, obsessivos, trágicas figuras que não representam bem o seu trabalho e que criam dificuldades aos seus colegas. Outros sugeriram que por vezes o workaholismo pode ser benéfico para os indivíduos ou para as organizações. Por exemplo, Galperin e Burke (2006) registam correlações positivas entre o envolvimento com o trabalho e a probabilidade de arrolar em comportamentos desviantes destrutivos para com a organização.

A relação do workaholismo com a saúde também é profusamente abordada. Andreassen et al. (2007) registam uma relação forte entre workaholismo e stress, burnout, e queixas subjectivas relacionadas com a saúde. Taris, Geurts, Schaufeli, Blonk e Lagerveld (2008) confirmam uma associação entre incapacidade de se desligar do trabalho e saúde percebida. Por outro lado, Vodanovich, Piotrowski e Wallace (2007) não encontram relações entre workaholismo e saúde (medidas: tensão sanguínea e enfartes do miocárdio).

Outros autores sugerem que o workaholismo relaciona-se de forma positiva com a satisfação com o trabalho e carreira (Machlowitz, 1980; Ng, Eby, Sorensen, \& Feldman, 2005). Em particular, aqueles que retiram prazer do trabalho e se sentem culpados ou ansiosos em actividades fora do trabalho sentem-se mais satisfeitos com o trabalho e a carreira.

$\mathrm{O}$ workaholismo pode também produzir alguns efeitos negativos a nível cognitivo, tais como saúde mental frágil, perfeccionismo e desconfian- 
ça para com os colegas ( $\mathrm{Ng}$ et al., 2007). O excesso de horas no trabalho pode traduzir-se de igual modo numa maior exposição ao stress, particularmente quando os workaholicos apresentam padrões de elevada performance. Outra consequência é a tendência para o perfeccionismo e para a perda de confiança nos colegas de trabalho.

Em termos de sucesso na carreira, aqueles que trabalham mais horas foram identificados como tendo mais sucesso extrínseco na carreira, incluindo salário e promoções ( $\mathrm{Ng}$ et al., 2005). No entanto, este sucesso na carreira tem os seus custos, que se podem catalogar em relações sociais pobres fora do trabalho, e fraca saúde física ( $\mathrm{Ng}$ et al., 2007).

No que respeita ao tempo (curto prazo e longo prazo), verifica-se que, por um lado, os workaholicos podem ser trabalhadores alegres e cheios de energia, dedicando mais horas ao trabalho do que os outros, daí resultando uma performance superior a curto prazo. Tal é confirmado, por exemplo, num estudo de Graves, Ruderman e Ohlott (2006), ao analisarem os efeitos das dimensões prazer com o trabalho e drive, na performance de gestores.

Por outro lado, os workaholicos podem apresentar uma saúde mental e física mais frágil, tal como relações sociais ténues, que podem reduzir a eficácia no trabalho a longo prazo. Por exemplo, Brady, Vodanovich e Rotunda (2008) corroboram a relação entre workaholismo, por um lado, e conflito trabalho-família e menor satisfação com os tempos de lazer, por outro.

\section{Objectivo da investigação}

Apesar dos estudos mencionados, pouco tem sido feito a nível empírico no que respeita ao workaholismo, e essas lacunas estendem-se, naturalmente, à existência de modelos e teorias sobre o fenómeno, a uma definição forte e consensual, assim como à relação com os seus antecedentes e consequentes. As propostas de $\mathrm{Ng}$ e colegas $(2007,2005)$, e de Liang e Chu (2009), sendo teórica e conceptualmente interessantes, carecem de confirmação empírica. Num curioso estudo empírico sobre as causas do workaholismo, Boje e Tyler (2009) usam a desconstrução dos discursos oriundos de autoetnografias, incluindo as de Jacques Derrida e do próprio David Boje, para concluir que por detrás do comportamento workaholico existem factores como a comparação social e a inveja, o que sugere que o fenómeno pode ser mais consciente do que as abordagens disposicional ou cultural, por exemplo.

O trabalho de Boje e Tyler é singular pela metodologia adoptada, mas também igualmente importante porque ilustra o potencial revelador das metodologias qualitativas em desvendar factores antes desconsiderados pelos modelos e autores a escrever sobre o tema. De facto, aspectos como a com- 
paração social e a inveja não haviam sido ainda contemplados até ao estudo de Boje e Tyler.

Face ao exposto, a presente investigação procura responder às questões de identificação e caracterização dos antecedentes e consequências do workaholismo, mas adopta uma metodologia qualitativa. Esta metodologia, que se pormenoriza em seguida, permite compreender o significado do workaholismo para os indivíduos por ele afectados.

\section{Método}

\section{Delineamento}

Tendo em conta o objectivo da investigação, e dada a escassez de trabalhos que levem em linha de conta a perspectiva dos próprios workaholicos, esta pesquisa é essencialmente exploratória, com uma orientação qualitativa. A opção por metodologias qualitativas permite dar voz aos participantes, e permite a pesquisa de fenómenos complexos que não são imediatamente reduzidos a variáveis quantitativas para inclusão em pesquisas ou designs experimentais (Krahn \& Putnam, 2003).

Visto que o fenómeno do workaholismo não é omnipresente, foi necessário recorrer a um despiste quantitativo para identificar sujeitos que reunissem as condições para a recolha da informação. Trata-se, assim, de uma pesquisa em duas fases: uma quantitativa (aplicação de questionários para aferição do grau de workaholismo), seguida de uma qualitativa (condução de entrevistas semi-estruturadas aos sujeitos com um maior grau de workaholismo). A fase quantitativa destinou-se a informar a qualitativa. $\mathrm{Na}$ notação de Tashakkori e Teddlie (1998), trata-se de uma metodologia mista sequencial em que a fase quantitativa tem como objectivo delimitar um ou mais aspectos da fase qualitativa, que é a predominante no trabalho. No presente caso, o aspecto a definir foi a triagem dos entrevistados.

\section{Participantes}

A primeira fase do estudo é baseada numa amostra de 33 sujeitos, 28 do sexo feminino e 5 do sexo masculino, com idades compreendidas entre os 22 e os 63 anos (média $=30,6$ e desvio padrão $=9,9$ ). Os sujeitos são colaboradores duma empresa de cosméticos de venda directa, e exercem funções no mesmo espaço físico em diferentes departamentos. A segunda fase do estudo abrange 10 sujeitos, 9 do sexo feminino e 1 do sexo masculino, com média de idades de 34,6 anos. Estes sujeitos pertenciam ao grupo da primeira fase do estudo, sendo que obtiveram os dez resultados mais elevados nos questionários. 


\section{Instrumento}

Para medir o workaholismo utilizou-se o Work Addiction Risk Test (Robinson, 1998), um questionário de auto-preenchimento com 25 itens numa escala tipo Likert de 4 pontos. A soma das respostas às questões resulta num valor que pode estar compreendido entre três níveis (Robinson, 1998): os do primeiro terço (67-100) são considerados extremamente workaholicos; os classificados no nível médio (57-66) são considerados workaholicos recuperáveis; e os classificados no nível inferior são considerados não workaholicos.

Foram ainda incluídas questões de índole biográfica, tais como: nome (importante para a segunda fase), sexo, idade, estado civil, anos de casamento ou de união de facto (caso o individuo seja casado ou se encontre em união de facto), número de filhos e respectivas idades, habilitações académicas, anos de trabalho na empresa, cargo ocupado na empresa, número de colaboradores da empresa, e média de horas de trabalho semanal.

$\mathrm{Na}$ fase qualitativa foi realizada uma entrevista a cada um dos dez sujeitos classificados no terço superior, e que correspondem aos extremamente workaholicos. O guião da entrevista foi desenvolvido com base na revisão da literatura (e em particular nos trabalhos de $\mathrm{Ng}$ e colaboradores) e no objectivo da investigação. Posteriormente, foi revisto pelos autores deste trabalho e por outros colegas, e finalmente foi feito um estudo piloto com dois entrevistados. Na sequência destes procedimentos, resultou um guião final composto por questões abertas, do género "que papel tem o trabalho na sua vida?", ou "já ouviu falar de 'workaholismo', ou seja, vício no trabalho? O que significa para si?". De notar que a entrevista foi do género semi-estruturada, pois não indagava directamente as pessoas sobre a sua extrema dedicação ao trabalho; ao invés, procurava saber a sua posição genérica sobre o tema. Com este procedimento, procurou-se ultrapassar a influência da admissão da condição de workaholico sobre as respostas.

\section{Resultados}

\section{Resultados do WART}

No que respeita aos 33 indagados, 13 não são considerados workaholicos, 14 revelam-se workaholicos recuperáveis e 6 surgem como extremamente viciados em trabalho. Pode concluir-se destes resultados que mais de metade dos trabalhadores (20) é afectada pelo workaholismo $(60,6 \%$; média $=58,5 ; \mathrm{DP}=8,9)$. Estas 20 pessoas apresentam uma média de idades de 29,9 anos e são maioritariamente do sexo feminino ( 2 do sexo masculino e 18 do sexo feminino). O estado civil predominante é solteiro (12 sujeitos). Quanto ao número de filhos, 12 indivíduos não têm filhos e 8 têm pelo menos um (6 
deles têm dois filhos). No que respeita às habilitações literárias, a maioria tem o $12^{\circ}$ ano de escolaridade ou superior ( $11 \mathrm{com}$ o $12^{\circ}$ ano e $5 \mathrm{com}$ licenciatura ou superior). Relativamente à função desempenhada, existe uma diversidade de cargos nestes sujeitos, tais como Assistentes de Apoio ao Cliente (3 sujeitos), Escriturárias (3 sujeitos), Assistentes de Marketing (2 sujeitos), Marketing Manager (2 sujeitos) e Coordenadores de Vendas (2 sujeitos). No que concerne o número de horas trabalhado, a maioria trabalha 40 horas semanais (13 sujeitos), verificando-se também 2 sujeitos que trabalham 45 horas semanais, 1 sujeito com 48 horas semanais, 3 com 50 horas semanais e 1 sujeito com 60 horas semanais.

Retirando a esta amostra de 20 sujeitos classificados como workaholicos os 10 com valores mais elevados, observa-se: a) média de idades $=34,6$ (desvio padrão $=11,0$ ); b) média de horas de trabalho semanal $=44,8$ (desvio padrão $=6,5$ ); c) estado civil: 5 solteiros; 1 união de facto; 4 casados; d) filhos: 5 sujeitos sem filhos e 5 sujeitos com filhos; e e) habilitações literárias: maioria com $12^{\circ}$ ano ou superior. A reduzida amostra não permite inferir sobre eventuais relações entre as variáveis biográficas e o workaholismo. Apesar de não ter sido objectivo deste trabalho, fica no entanto a sugestão de que pesquisas futuras devam considerar estas variáveis como factores a controlar ou mesmo a explorar na sua relação com o workaholismo.

\section{Resultados das Entrevistas}

As entrevistas foram analisadas com recurso à técnica de análise de conteúdo (Vala, 1999). Os procedimentos analíticos foram elaborados a partir da literatura especializada (e.g. Bardin, 2008; Krippendorff, 1980; Silverman, 1997). Como se referiu atrás, partiu-se de alguns grupos de questões (categorias) para estruturar a entrevista, na sequência do objectivo da pesquisa e dos trabalhos de $\mathrm{Ng}$ e colegas. Importante mencionar que a unidade de registo principal foi o tema, normalmente realçado numa frase (unidade de contexto), muito embora tivessem sido identificadas instâncias em que emerge mais do que um tema por frase. A figura 2 ilustra o processo seguido para analisar o texto das entrevistas.

Deste processo resultaram quatro categorias: significado do workaholismo, opinião sobre os workaholicos, antecedentes, e consequentes. Cada uma destas categorias possui várias subcategorias (figura 3). A figura 3 detalha ainda o registo via algumas unidades de enumeração, nomeadamente a frequência relativa das categorias e subcategorias. Na totalidade, as 10 entrevistas produziram 89 troços de texto codificável, sendo que, destes, $32,5 \%$ não foram codificados dado dizerem respeito a outros temas de conversa (e.g. fase de aquecimento nas entrevistas). 60 troços de texto foram codificados, o que corresponde a $67,5 \%$ de texto analisado e traduzido para categorias relevantes para o presente trabalho. 
Figura 2 - Processo de análise de conteúdo das entrevistas a workaholicos

\begin{tabular}{|c|c|c|}
\hline Passos & Técnica & Objectivo \\
\hline $1^{\circ}$ & Audição das entrevistas & Apreender ideia geral de cada entrevista \\
\hline $2^{\circ}$ & Transcrição das Entrevistas & Organizar o texto e deter ideias gerais \\
\hline $3^{\circ}$ & $\begin{array}{l}1^{\circ} \text { Nível de Codificação } \\
\text { Cores }\end{array}$ & $\begin{array}{l}\text { Identificação das respostas específicas } \\
\text { a cada questão }\end{array}$ \\
\hline $4^{\circ}$ & $\begin{array}{l}2^{\circ} \text { Nível de Codificação } \\
\text { Lista de itens }\end{array}$ & $\begin{array}{l}\text { Identificação dos vários itens correspondentes } \\
\text { a cada questão }\end{array}$ \\
\hline $5^{0}$ & $\begin{array}{l}1^{\circ} \text { Nível de Categorização } \\
\text { Agrupamento }\end{array}$ & $\begin{array}{l}\text { Agrupamento de itens semelhantes } \\
\text { em categorias provisórias }\end{array}$ \\
\hline $6^{\circ}$ & $\begin{array}{c}2^{\circ} \text { Nível de Categorização } \\
\text { Homogeneização }\end{array}$ & $\begin{array}{l}\text { Homogeneização das categorias } \\
\text { das várias respostas }\end{array}$ \\
\hline
\end{tabular}

Figura 3 - Tabela de codificação de subtemas e respectivas categorias

\begin{tabular}{cccc}
\hline Categorias & Subcategorias & $\begin{array}{c}\text { \# (\%) Entrevis- } \\
\text { tas em que a } \\
\text { subcategoria } \\
\text { está presente }\end{array}$ & $\begin{array}{c}\text { \# Ocorrências / Inten- } \\
\text { sidade dentro da cate- } \\
\text { goria maior }\end{array}$ \\
\hline \multirow{2}{*}{$\begin{array}{c}\text { Significado do } \\
\text { workaholismo }\end{array}$} & Obsessão com o trabalho & $9(90 \%)$ & $10 / 53 \%$ \\
\cline { 2 - 4 } & Centralidade & $3(30 \%)$ & $5 / 26 \%$ \\
\hline \multirow{2}{*}{$\begin{array}{c}\text { Opinião sobre } \\
\text { workaholicos }\end{array}$} & Dependência & $3(30 \%)$ & $4 / 21 \%$ \\
\hline $\begin{array}{c}\text { Antecedentes } \\
\text { do workaho- } \\
\text { lismo }\end{array}$ & Factores organizacionais & $4(40 \%)$ & $16 /$ não aplicável \\
\cline { 2 - 4 } & Factores sociais & $5(50 \%)$ & $4 / 21 \%$ \\
\hline $\begin{array}{c}\text { Consequências } \\
\text { do workaho--- }\end{array}$ & Factores individuais & $8(80 \%)$ & $5 / 26 \%$ \\
\cline { 2 - 4 } \begin{tabular}{c} 
lismo \\
\cline { 2 - 4 }
\end{tabular} & Factores sociais & $6(60 \%)$ & $9 / 41 \%$ \\
\hline
\end{tabular}


Categoria 1: Significado do workaholismo

As subcategorias resultantes neste primeiro grupo foram: Obsessão com o Trabalho, Centralidade e Dependência.

a) Obsessão com o trabalho: comportamentos relacionados com a incapacidade de parar de trabalhar ou de pensar no trabalho dentro e fora do local de trabalho. Esta categoria esteve presente num grande número de entrevistas, o que implica necessariamente que é uma das mais associadas pelos sujeitos ao workaholismo. Uma resposta típica neste grupo foi "alguém que não consegue parar de trabalhar".

b) Centralidade: papel central que o trabalho ocupa na vida dos indivíduos colocando em segundo plano outras áreas da vida que perdem importância. Tal como na categoria anterior, registou-se um largo número de respostas enquadradas no âmbito desta categoria, o que se traduz na sua grande importância na definição de workaholismo no presente estudo. Um entrevistado referiu que um workaholico é "alguém que tem como prioridade o trabalho". É interessante verificar que cada vez mais as pessoas reconhecem que o trabalho lhes consome uma grande parte dos seus dias e das suas próprias vidas, restando pouco tempo para outras actividades ou mesmo para outras pessoas fora do âmbito laboral. As pessoas acabam por despender mais tempo das suas vidas junto dos colegas de trabalho do que com os seus familiares ou amigos, quer seja por necessidade ou simplesmente por dedicação extrema ao trabalho que se desempenha.

c) Dependência: adição desenvolvida pelos sujeitos face ao trabalho. Esta seria uma categoria previsível dada a constituição da própria palavra workaholismo, que leva os sujeitos a associarem o conceito a um comportamento aditivo (tal como o alcoolismo, noção claramente conhecida por todos os indivíduos). No entanto, esta subcategoria foi a menos referenciada neste grupo, tendo sido referenciada apenas por três sujeitos.

\section{Categoria 2: Opiniões sobre workaholicos}

Em relação à opinião dos sujeitos sobre os workaholicos não foram geradas subcategorias, sendo no entanto interessante analisar algumas das respostas retiradas das entrevistas. Privação da vida pessoal em detrimento do trabalho e falta de tempo para si próprios foram as críticas mais apontadas pelos sujeitos. Alguns dos entrevistados revelaram um sentimento de pesar em relação aos workaholicos referindo que "não tem muita vida social e só sai de casa para o trabalho e do trabalho para casa" ou "penso que essa pessoa se deixa absorver muito, dedicando muito pouco tempo a si própria". Outros sujeitos apresentaram opiniões que revelaram alguma reprovação em relação aos workaholicos tais como "acho que de maneira nenhuma compensa uma atitude dessas perante a vida" ou "parece viver exclusivamente 
para o trabalho e não tem outros interesses para além dele”. É de referir que três dos dez sujeitos entrevistados apontaram não conhecer ninguém workaholico e, por isso, não ter nenhuma opinião formada; ainda assim, foram capazes de emitir algumas opiniões.

\section{Categoria 3: Antecedentes do workaholismo}

No que respeita aos factores que podem fomentar o aparecimento de workaholismo podem dividir-se em três grupos: organizacionais, sociais e individuais.

a) Factores organizacionais: incluem conceitos inerentes à cultura $\mathrm{e}$ funcionamento da organização, que desencadeiam comportamentos considerados workaholicos, tais como competitividade, responsabilidade e ambiente de trabalho. Esta categoria relaciona o excesso de trabalho com as características da própria organização, o que pode indiciar que haverá locais de trabalho mais propensos ao desenvolvimento de workaholismo do que outros, consoante os seus valores e as suas práticas.

b) Factores sociais: episódios da vida social que podem conduzir ao workaholismo, tais como solidão, falta de amigos ou outro tipo de carências de cariz social em que o trabalho aparece como um refúgio. Esta categoria vem a ser largamente mencionada (e.g. "uma falta em outros domínios, que vem ser compensada pelo trabalho"), indiciando que este é um factor que muito afecta os indivíduos de modo a quererem dedicar-se excessivamente ao trabalho para colmatar falhas ou mesmo ausência de vida social.

c) Factores individuais: inclui atributos pessoais ou relativos ao sujeito que são favoráveis ao desenvolvimento de comportamento workaholico, tais como ambição, gosto pelo trabalho, necessidade de afirmação. $\mathrm{O}$ gosto por aquilo que se faz é o que mais se destaca nesta categoria pelo número de ocorrências nas entrevistas, o que aponta para um factor chave para se querer trabalhar mais, tanto que acaba por ser desmesurado e nocivo para outras áreas da vida do sujeito, como a vida pessoal (como se verá mais à frente). As respostas incluem quer elementos positivos ("gostar muito do que faz e trabalhar por amor à camisola"), quer negativos ("a ganância e vontade de ir mais além”).

\section{Categoria 4: Consequências do workaholismo}

Quanto aos efeitos do workaholismo na vida das pessoas, as respostas indiciam especialmente os de nível pessoal, social e saúde. Deste modo, as subcategorias encontradas são factores: emocionais, sociais e saúde.

a) Factores emocionais: aspectos relativos aos danos provocados pelo workaholismo na vida afectiva e pessoal do sujeito, tais como isolamento, solidão, problemas familiares, perda de valores, e depressão. Estes factores 
assolam a vida dos sujeitos e podem trazer consequências dolorosas e de instabilidade emocional. Por despenderem tanto tempo a trabalhar ou a pensar no trabalho as pessoas negligenciam ou prejudicam a sua vida pessoal.

b) Factores sociais: aspectos da vida social que podem resultar de comportamentos workaholicos, tais como exclusão. Este tema surge em várias respostas, pelo que se considera pertinente a sua nomeação. O tema deixa antever uma marginalização feita pela própria sociedade. A ideia de alguém que trabalha demasiado ou que se dedica excessivamente às suas funções pode muitas vezes ser interpretada como um comportamento desajustado socialmente.

c) Factores de saúde: consequências físicas e psicológicas prejudiciais à saúde dos indivíduos que manifestam comportamentos workaholicos, tais como cansaço, e stress. Estes factores remetem directamente para o estado de saúde dos sujeitos que pode ser nefastamente alterado pelo excesso de esforço e tempo aplicados no e para o trabalho.

\section{Outros dados relevantes}

Deve ainda acrescentar-se que relativamente à correspondência entre os resultados obtidos nos questionários e nas entrevistas existem alguns dados interessantes de ser analisados, tais como o facto de os sujeitos se considerarem ou não workaholicos e o serem efectivamente (de acordo com a escala do questionário de Robinson, 1998).

Dos dez sujeitos entrevistados, apenas três se consideram efectivamente workaholicos, nomeadamente os que obtiveram as pontuações mais elevadas no questionário (dois com 73 e um com 71 pontos). Houve ainda um quarto sujeito que se classificou como sendo um pouco workaholico, curiosamente o que dos dez apresentava a classificação mais baixa (63 pontos). Os restantes seis sujeitos afirmaram não se considerarem workaholicos, pelo menos de acordo com aquilo que significa para si esse conceito.

Outro aspecto a considerar é a relação entre o significado que os sujeitos atribuem ao trabalho e considerarem-se ou não workaholicos. Todos os entrevistados indicam que o trabalho é de grande importância nas suas vidas. No entanto, verifica-se que os quatro sujeitos que se consideram workaholicos dão maior ênfase à envolvência e realização pessoal inerente ao trabalho do que à sua componente financeira e de subsistência, como acontece com a maioria daqueles que não consideram ser afectados pelo workaholismo.

Finalmente, comparando as respostas dadas pelos sujeitos à pergunta 3 da entrevista ("considera-se workaholico? Porquê?"), e o número de horas de trabalho semanais reportadas nos questionários, pode dizer-se que os sujeitos que se consideram workaholicos são efectivamente os que reportam trabalhar mais horas por semana: os três sujeitos que confirmam ser worka- 
holicos trabalham entre 48 a 60 horas semanais; o sujeito que se considera um pouco workaholico trabalha 45 horas semanais; todos os restantes sujeitos que não se auto-proclamam workaholicos, trabalham abaixo das 45 horas por semana.

\section{Discussão e conclusões}

Este estudo teve como objectivo principal compreender os antecedentes e consequentes do workaholismo, tal como percebidos pelos próprios workaholicos. Buscou-se ainda explorar o significado do termo, também de um ponto de vista subjectivo.

A pesquisa revelou algumas semelhanças ao nível da definição de workaholismo em relação à definição de Oates (1971), uma vez que a maioria das respostas apresentadas se refere a uma obsessão pelo trabalho, uma incapacidade em parar de trabalhar ou de pensar no trabalho, assemelhando-se a outro tipo de dependências.

É afirmada de igual modo a definição de Moisier (1983), na qual o workaholismo é definido pelo número de horas trabalhadas. Apesar de não ser apenas este o critério defendido neste estudo para definir o workaholismo como o autor fez, a verdade é que os sujeitos entrevistados que se auto-intitulam de workaholicos trabalham acima das 48 horas semanais, o que pode levar a considerar este critério com alguma legitimidade.

Scott et al. (1997) apontaram alguns elementos básicos na identificação de indivíduos com padrões de comportamento workaholico: parte do tempo gasto em actividades de trabalho; muita importância atribuída ao mesmo; pouca importância a outros aspectos sociais - família, amigos, lazer...; pensar frequentemente em assuntos de trabalho, mesmo quando não se está a trabalhar; trabalhar muito além do que é razoavelmente esperado do cargo. Esta definição vai de encontro ao que se conseguiu apurar neste estudo, nomeadamente o tempo que os sujeitos despendem no trabalho em detrimento da vida pessoal ou social. Estes resultados foram claramente identificados nas entrevistas, tanto ao nível da obsessão no trabalho, que impede os indivíduos de parar de trabalhar ou de pensar no trabalho, como ao nível do afastamento de amigos e familiares. Outro aspecto a salientar é que os entrevistados não apontaram o factor económico como determinante do comportamento workaholico, o que é coerente com a ideia de que os indivíduos são motivados por forças internas e não por factores externos (Burke, 2001).

Para além disso, Scott et al. (1997) preferem interpretar o workaholismo como o resultado de variáveis pessoais, embora considerem que variáveis situacionais possam constituir um factor chave no desenvolvimento e 
manifestação dos comportamentos analisados. Aqui também surgem afinidades com os resultados apurados, em que, apesar do peso dos factores individuais, é indispensável também ter em conta os aspectos organizacionais que determinam o aparecimento de workaholismo. Esta é uma contribuição importante do presente trabalho, pois os factores organizacionais tinham sido raramente considerados (excepções recentes incluem os artigos de Galperin \& Burke, 2006, e Liang \& Chu, 2009).

Apesar das diversas definições e tipologias de workaholismo na literatura, há alguma harmonia relativamente ao facto do workaholismo estar associado a consequências adversas de saúde, e a uma reduzida satisfação com a família ou outro tipo de relações interpessoais (Burke, 2000; Robinson, 1998; Killinger, 1991; Spence \& Robbins, 1992; Taris et al., 2008). A presente investigação veio também corroborar este aspecto, pois verificaram-se algumas referências ao nível dos efeitos nefastos na saúde dos indivíduos, tal como problemas gerados ao nível da vida familiar e mesmo de outras relações (e.g. amizade).

$\mathrm{Ng}$ et al. (2007) definem três dimensões no workaholismo: afectiva, cognitiva e comportamental. Os workaholicos retiram prazer do acto de trabalhar, estão obcecados pelo trabalho, e nele investem longas horas e tempo livre pessoal. Muitos entrevistados salientaram o gosto pelo que se faz como um factor catalisador de workaholismo, tal como a incapacidade em parar ou desligar-se do trabalho, mesmo fora do ambiente laboral.

No que diz respeito aos antecedentes do workaholismo, a literatura sintetiza três perspectivas baseadas em comportamentos aditivos: disposições individuais, experiências socioculturais e comportamentos reforçados pelo ambiente. As disposições individuais têm um papel fundamental na generalidade dos comportamentos aditivos e, como tal, também se reflecte no workaholismo. São relevantes: a auto-estima, os traços de personalidade relacionados com a realização e os valores do indivíduo.

Uma das influências disposicionais mais importantes é a auto-estima, estando negativamente relacionada com o comportamento workaholico. No presente estudo, não se verificaram respostas neste sentido, não havendo qualquer referência ao índice de auto-estima dos indivíduos como catalisador do workaholismo.

No que respeita a traços de personalidade relacionados com a realização (como personalidade Tipo-A, comportamento obsessivo-compulsivo e necessidade de realização), não foram enquadrados pelos sujeitos no âmbito dos antecedentes do workaholismo, mas antes na sua própria definição. Isto significa que os sujeitos do estudo identificam efectivamente este tipo de traços de personalidade como inerentes a pessoas workaholicas. Este é outro resultado relevante, dada a inconsistência observada na literatura sobre a 
relação entre personalidade e workaholismo (Andreassen et al., 2010; Liang \& Chu, 2009).

No que concerne os valores mais relevantes para despoletar o workaholismo, a literatura (Ng et al., 2007) sugere o desejo de se ser bem sucedido, capaz, ambicioso e influente; e ainda a auto-orientação, que reflecte uma direcção para a independência. Neste estudo, a ambição é dada como um dos factores conducentes ao workaholismo. Em relação aos valores de auto-orientação, não foram verificadas citações no presente estudo.

A perspectiva baseada nas experiências sócio-culturais sugere que a dependência é geralmente o produto das experiências sociais e culturais que as pessoas vivem durante a infância, adolescência e fase adulta (Thombs, 1994, citados por $\mathrm{Ng}$ et al., 2007). Esta perspectiva é altamente apoiada pelas respostas obtidas nesta pesquisa, em que vários sujeitos apontam a carência de vida pessoal como factor motivador do workaholismo.

As experiências sócio-culturais nascem frequentemente dentro da família ou no local de trabalho ( $\mathrm{Ng}$ et al., 2007). Do lado familiar, um leque de experiências negativas podem precipitar o workaholismo, e o trabalho pode ser visto como um modo socialmente aceite de evitar a família. Esta convicção está presente neste estudo, em que é apontado que o excesso de trabalho pode servir como um refúgio da vida familiar.

As experiências sociais nas organizações também podem desencadear o workaholismo. Nas organizações o observar de comportamentos workaholicos em supervisores ou em colegas - tal como excesso de horas de trabalho e negligência da vida pessoal - pode induzir a respostas copiadas por outros funcionários ( $\mathrm{Ng}$ et al., 2007). Os comportamentos workaholicos dos pares podem evocar comportamentos workaholicos nos indivíduos devido à atmosfera competitiva generalizada que o workaholismo produz (Boje \& Tyler, 2009; Seybold \& Salomone, 1994). Esta concepção está claramente implícita na competitividade apontada pelos entrevistados, pois se há ostentações na organização de quem trabalhe mais que outros e que daí seja mais bem cotado pelos superiores, isto leva a que outros queiram competir com os primeiros, adoptando os mesmos métodos ou laborando ainda mais.

$\mathrm{Na}$ perspectiva dos comportamentos reforçados pelo ambiente, vários estudos sugerem que o seu início é resultado de reforços positivos de comportamentos workaholicos ou da falta de punição dessas acções. Por conseguinte, quando os funcionários se apercebem de que o workaholismo é recompensado, eles tendem a alimentar essas acções de modo a continuarem a ser recompensados ( $\mathrm{Ng}$ et al., 2007). Esta perspectiva não foi, no entanto, detectada no presente estudo.

No que concerne as consequências do workaholismo, as investigações enfatizam o seu lado negativo (e.g. Killinger, 1991), muito embora alguns trabalhos sugerem haver benefícios para indivíduos e organizações (e.g. Mach- 
lowitz, 1980). Os dados obtidos neste estudo corroboram a perspectiva negativa, havendo apenas uma resposta de carácter positivo (progressão na carreira). Todas os restantes sujeitos focam factores nocivos como o afastamento de amigos e família, problemas pessoais e de saúde, ou perda de valores.

As consequências do workaholismo são analisadas segundo várias perspectivas: satisfação com o trabalho e carreira; saúde mental, perfeccionismo e desconfiança; sucesso na carreira, relações sociais e saúde física; e o papel do tempo (curto prazo vs longo prazo).

Várias pesquisas sugerem que o workaholismo está positivamente relacionado com a satisfação com o trabalho e carreira (Ng et al., 2005). No presente estudo há apenas a referência ao gosto por aquilo que se faz sendo um dos antecedentes citados pelos sujeitos que desencadeiam o comportamento workaholico.

O workaholismo pode também produzir efeitos negativos a nível cognitivo, tais como saúde mental frágil, perfeccionismo e desconfiança para com os colegas. Os resultados do presente trabalho apontam para efeitos nefastos ao nível da saúde mental (como o cansaço ou perturbações causadas pelo stress). O perfeccionismo é também associado ao workaholismo, sendo ligado pelos sujeitos à definição do próprio conceito. No que respeita à desconfiança para com os colegas não se verificaram ocorrências nas entrevistas efectuadas.

Em termos de sucesso na carreira, aqueles que trabalham mais horas são identificados como tendo mais sucesso extrínseco na carreira, incluindo salário e promoções ( $\mathrm{Ng}$ et al., 2005). No entanto, este sucesso na carreira tem custos: relações sociais pobres fora do trabalho e fraca saúde física. Neste estudo, apenas um sujeito identificou a possibilidade de progressão na carreira como um dos efeitos do workaholismo, não havendo alusão a factores monetários, como o aumento de salário. Em relação aos custos acarretados pelo sucesso na carreira, foram referidas pelos sujeitos as relações sociais pobres e problemas de saúde.

Com esta pesquisa promoveu-se essencialmente uma reflexão sobre alguns aspectos do mundo do trabalho na actualidade, nomeadamente sobre o fenómeno do workaholismo. Foi alcançado o objectivo de investigação inicialmente proposto, conseguindo-se encontrar alguns significados associados ao workaholismo, bem como identificar alguns antecedentes e consequências associados a esta problemática. Todavia, o presente estudo enferma do número reduzido de participantes, o que limita à partida a variabilidade de respostas encontradas assim como a generalização dos resultados. A saturação teórica foi parcialmente encontrada durante as entrevistas, o que determinou a restrição da recolha de dados a 10 casos, mas a panóplia de sub-temas no vasto território do workaholismo suscitou tantas questões quantas as que foram respondidas no final do estudo. Por exemplo, nesta 
pesquisa não se exploraram as relações entre o workaholismo e as variáveis biográficas. Em parte porque não era este o objectivo do trabalho, mas também porque a reduzida amostra numa única empresa não poderia revelar padrões de elevada qualidade no que à extrapolação diz respeito. Investigações futuras com amostras representativas e de maior dimensão podem e devem averiguar se o workaholismo afecta todas as pessoas de igual forma.

Outra das dificuldades sentidas foi a escassez de informação disponível, mormente no que respeita a estudos feitos em Portugal. Neste caso concreto não foi encontrado nenhum, o que sugere que pouco tem sido feito em torno desta temática no país. A evidência existente é sobretudo de carácter anedótico ou jornalístico, o que condiciona um desenvolvimento científico do problema.

Dado que o presente estudo foi realizado numa única organização, as conclusões são igualmente limitadas a esse ambiente. Importa, por isso, perceber se os factores encontrados emergem noutros contextos, nomeadamente em outras organizações. Particularmente estimulante e curiosa pode ser a exploração do workaholismo em ambientes altamente competitivos, como a banca ou a consultoria.

Revelar se o workaholismo está mais ou menos presente num dos géneros (feminino e masculino) seria também um estudo pertinente a conduzir, uma vez que cada género, ao cumprir funções distintas na sociedade, pode estar mais ou menos exposto ao fenómeno. Seria ainda útil averiguar se existem profissões onde o workaholismo tenha maior expressão, bem como se existem culturas organizacionais que promovam este padrão comportamental.

Em suma, muitas investigações poderão e deverão seguir a presente pesquisa, explorando diferentes áreas ou problemas para que este tema seja melhor compreendido na teoria e nas organizações.

\section{Referências}

Andreassen, C.S., Hetland, J. \& Pallesen, S. (2010). The relationship between 'workaholism', basic needs satisfaction at work and personality. European Journal of Personality, 24, 3-17.

Andreassen, C.S., Ursin, H. \& Eriksen, H.R. (2007). The relationship between strong motivation to work, "workaholism", and health. Psychology and Health, 22(5), 615-629.

Aziz, S., Adkins, C.T., Walker, A.G. \& Wuensch, K.L. (2010). Workaholism and work-life imbalance: Does cultural origin influence the relationship? International Journal of Psychology, 45(1), 72-79.

Aziz, S. \& Zickar, M.J. (2006). A cluster analysis investigation of workaholism as a syndrome. Journal of Occupational Health Psychology, 11(1), 52-62. 
Bardin, L. (2008). Análise de conteúdo. Lisboa: Edições 70.

Brady, B.R., Vodanovich, S.J. \& Rotunda, R. (2008). The impact of workaholism on work-family conflict, job satisfaction, and perception of leisure activities. The Psychologist-Manager Journal, 11, 241-263.

Boje, D. \& Tyler, J.A. (2008). Story and narrative noticing: Workaholism autoethnographies. Journal of Business Ethics, 84, 173-194.

Burke, R.J. (2001). Workaholism components, job satisfaction, and career progress. Journal of Applied Social Psychology, 31, 2339-2356.

Burke, R.J. (2000). Workaholism in organizations: Concepts, results and future research directions. International Journal of Management Reviews, 2 (1), 1-16.

Chamberlin, C. \& Zhang, N. (2009). Workaholism, health, and self-acceptance. Journal of Counseling \& Development, 87, 159-169.

Galperin, B.L. \& Burke, R.J. (2006). Uncovering the relationship between workaholism and workplace destructive and constructive deviance: An exploratory study. International Journal of Human Resource Management, 17(2), 331-347.

Grave, L.M., Ruderman, M.N. \& Ohlott, P.J. (2006). Effect of workaholism on managerial performance: Help or hindrance? Academy of Management Best Conference Paper, A1-A6.

Gorgievski, M.J., Bakker, A.B. \& Schaufeli, W.B. (2010). Work engagement and workaholism: Comparing the self-employed and salaried employees. The Journal of Positive Psychology, 5(1), 83-96.

Killinger, B. (1991). Workaholics: The respectable addicts. Buffalo, NY: Firefly.

Krahn, G.L. \& Putnam, M. (2003). Qualitative Methods in Psychological Research. In M. Roberts \& S. Ilardi (Eds.), Handbook of Research Methods in Clinical Psychology (pp. 177-192). Oxford: Blackwell Publishing Ltd.

Krippendorff, K. (1980). Content Analysis: An Introduction to its Methodology. London: Sage.

Liang, Y.-W. \& Chu, C.-M. (2009). Personality traits and personal and organizational inducements: Antecedents of workaholism. Social Behavior and Personality, 37(5), 645-660.

Machlowitz, M. (1980). Workaholics: Living with them, working with them. Reading, MA: Addison Wesley.

Mosier, S.K. (1983). Workaholics: An analysis of their stress, success and priorities. Unpublished master's thesis, University of Texas at Austin.

Naughton, T.J. (1987). A conceptual view of workaholism and implications for career counseling and research. The Career Development Quarterly, 14, 180$-187$.

Ng, T.W.H., Eby, L.T., Sorensen, K.L. \& Feldman, D.C. (2005). Predictors of objective and subjective career success: A meta-analysis. Personnel Psychology, 58, 367-408.

Ng, T.W.H., Sorensen, K.L. \& Feldman, D.C. (2007). Dimensions, antecedents, and consequences of workaholism: A conceptual integration and extension. Journal of Organizational Behaviour, 28(1), 111-136. 
Oates, W. (1971). Confessions of a Workaholic: The Facts about work addiction. New York: World.

Porter, G. (1996). Organizational impact of workaholism: Suggestions for researching the negative outcomes of excessive work. Journal of Occupational Health Psychology, 1, 70-84.

Robinson, B.E. (1998). Chained to the desk: A guidebook for workaholics, their partners and children and the clinicians who treat them. New York: New York University Press.

Robinson, B.E. \& Post, P. (1997). Risk of addiction to work and family functioning. Psychological Reports, 81, 91-95.

Robinson, B.E. \& Kelley, L. (1998). Adult children of workaholics: Self-concept, anxiety, depression, and locus of control. The American Journal of Family Therapy, 26, 223-238.

Scott, K.S., Moore, K.S. \& Miceli, M.P. (1997). An exploration of the meaning and consequences of workaholism. Human Relations, 50, 287-314.

Serva, M. \& Ferreira, J.L.O. (2006). O fenómeno workaholic na gestão de empresas. RAP Rio de Janeiro, 40 (2), 179-200.

Seybold, K.C. \& Salomone, P.R. (1994). Understanding workaholism: A review of causes and counselling approaches. Journal of Counselling and Development, 73, 4-9.

Silverman, D. (1997). Interpreting qualitative data: Methods for analysing talk, text, and interaction, London: Sage.

Spence, J.T. \& Robbins, A.S. (1992). Workaholism: Definition, measurement, and preliminary results. Journal of Personality Assessment, 58 (1), 160-178.

Taris, T.W., Schaufeli, W.B. \& Verhoeven, L.C. (2005). Workaholism in the Netherlands: Measurement and implications for job strain and work-nonwork conflict. Applied Psychology: An International Review, 54 (1), 37-60.

Taris, T.W., Geurts, S.A.E., Schaufeli, W.B., Blonk, R.W.B. \& Lagerveld, S.E. (2008). All day and all of the night: The relative contribution of two dimensions of workaholism to well-being in self-employed workers. Work \& Stress, 22(2), 153-165.

Tashakkori, A. \& Teddlie, C. (1998). Mixed Methodology: Combining Qualitative and Quantitative Approaches, Thousand Oaks: Sage.

The Economist (2007). Jobs for life: Japanese employees are working themselves to death. The Economist, $19^{\text {th }}$ December.

Vala, J. (1999). A análise de conteúdo. In A. Silva \& J. Madureira (Eds.), Metodologia das Ciências Sociais (pp. 101-128). Porto: Edições Afrontamento.

Vodanovich, S.J., Piotrowski, C. \& Wallace, J.C. (2007). The relationship between workaholism and health: A report of negative findings. Organization Development Journal, 25(1), 70-75. 